\title{
Exploring and Addressing Contract Faculty Disengagement with Regards to Institutional Policy on Pedagogy
}

\author{
Frederic Fovet
}

Royal Roads University

\begin{abstract}
An increasing percentage of faculty on North American campuses are contract employees. They work part-time and often on evenings and weekends, meaning their contact with core faculty may be reduced and their exposure to professional development limited. Many report a weak sense of affiliation with the campuses they work on.

The project explored hurdles and opportunities in sustaining Associate Faculty interest in and commitment to the Learning Teaching Research Model (LTRM) within the MA in Educational Leadership and Management Program at Royal Roads University. This Action Research initiative had identified a need: embedding the LTRM into the MAELM program and examining contract faculty perspectives as this work unfolded. It sought concrete solution to reduce the isolation experienced by contract faculty vis-a-vis institutional policy on pedagogy.

The issue identified within the environment was the possible disconnect contract faculty experience with regards to a centralized, institutional pedagogical framework. The study sought to identify solutions to erode detachment on the part of contract faculty and ensure a continued focus on the core values of the pedagogical model. The specific tools relied on within this methodological approach were phenomenological and ethnographic. A first part of the analysis focused on the phenomenological exploration of the Program Head's experience through these redesign steps (journaling and video diary). A second chapter of the analysis sought to examine and categorize the facilitators and stressors that were discussed by contract faculty both in semi-directive interviews and interactions with core faculty and school administration through the delivery of courses.
\end{abstract}

Outcomes highlight the need to address the way contract faculty perceive and embrace institutional models for excellence in pedagogy. This section offers hands on solutions to reduce stressors and capitalize on facilitators.

Keywords: contract faculty, pedagogical reform, action research, institutional pedeagogical frameworks 